\title{
REMOÇÃO DE ESTRUTURAS VEGETATIVAS NOS ESTÁDIOS INICIAIS SOBRE CARACTERÍSTICAS PRODUTIVAS E MORFOFISIOLÓGICAS DA SOJA
}

\author{
Renan Ribeiro Barzan ${ }^{1}$, Gustavo Henrique Freiria ${ }^{1}$, Vitor Camargo do Nascimento Junior ${ }^{2}$, \\ Cássio Egídio Cavenaghi Prete ${ }^{3}$ \\ ${ }^{1}$ Doutorando em Agronomia pela Universidade Estadual de Londrina. \\ ${ }^{2}$ Doutor em Agronomia pela Universidade Estadual de Londrina. \\ ${ }^{3}$ Professor doutor em fitotecnia pela Universidade Estadual de Londrina, Londrina (PR).
}

RESUMO: O objetivo deste estudo foi avaliar o desempenho produtivo e as características da soja após a remoção de estruturas vegetativas no desenvolvimento inicial. O trabalho foi conduzido na Fazenda Escola da UEL, nas safras 2012/13 e 2013/14, utilizando a cultivar BRS 360 RR, num delineamento em blocos casualizados com quatro tratamentos e cinco repetições. Os tratamentos foram: 1- Testemunha; 2- Remoção dos cotilédones em VC; 3Corte do caule acima do nó cotiledonar em V1; 4- Corte do caule acima do nó das folhas primárias em V2. Avaliaram-se, em ambas as safras, a produtividade de grãos $\left(\mathrm{kg} \mathrm{ha}^{-1}\right)$ e, somente na primeira safra, os componentes do rendimento e características morfológicas como número de ramos, número de nós da haste principal, altura e diâmetro do colo. Os dados foram submetidos à análise de variância $(p<0,05)$ e as médias comparadas pelo teste de Tukey à 5\%. Em ambas as safras, observou-se redução da produtividade apenas nos tratamentos 3 e 4 em relação à testemunha. $\mathrm{O}$ número de legumes por planta foi o único componente do rendimento com diferenças significativas, diminuindo nos tratamentos 3 e 4 . Ainda, houve maior ramificação e número de nós nos tratamentos 1 e 2, enquanto estes tratamentos proporcionaram maiores alturas e menores diâmetros do colo. Conclui-se que o corte do caule acima do nó cotiledonar e acima do nó das folhas primárias prejudica a produtividade e as características morfofisiológicas da soja.

Palavras-chave: Glycine max L. Merrill. Plântulas. Injúrias.

\section{VEGETATIVE STRUCTURES REMOVAL AT INITIAL DEVELOPMENTAL STAGES OVER PRODUCTIVE AND MORFOPHYSIOLIGICAL CHARACTERISTICS OF SOYBEAN}

\begin{abstract}
The aim of this study was to evaluate botanic characteristics and productive response of soybean after vegetative structures removal at initial developmental stages. The work was conducted in State University of Londrina Farm School, in 2012/13 and 2013/14 seasons, using BRS 360 RR cultivars, in a randomized block design with four treatments and five replications. The treatments were: 1- Control; 2- Cotyledon removal at VC; 3- Stem cut above cotyledonary node at V1; 4- Stem cut above unifoliolate node at V2. It was evaluated, at both seasons, the grain yield $\left(\mathrm{kg} \mathrm{ha}^{-1}\right)$ and, only at the first season, the yield components and morphological characteristics such as the number of branches, the number
\end{abstract}

Cultura Agronômica, Ilha Solteira, v.25, n.1, p.17-24, 2016 
of nodes in the main stem, plant height and lap diameter. The data were submitted to ANOVA and the averages were compared with Tukey test at 5\%. In both harvests, there is reduced productivity only in treatments 3 and 4 in relation to the control. The number of pods per plant was the single component with significant yield differences decreasing in treatments 3 and 4. Also, there has been increased branching and number of nodes in treatments 1 and 2, while these treatments showed greatest heights and diameters smaller lap. In conclusion, cutting the stem above the cotyledon node and above the node of the primary leaves affect the productivity and morphological and physiological characteristics of soybean.

Key words: Glycine max L. Merrill. Seedlings. Injuries.

\section{INTRODUÇÃO}

O desempenho produtivo na cultura da soja resulta da combinação entre fatores relacionados à planta, como genética e características morfofisiológicas (número de nós e ramos, diâmetro de hastes, área foliar, atividade fotossintética, etc.), bem como fatores relacionados ao ambiente de produção e manejo, a exemplo das condições climáticas e interação com plantas competidoras, pragas e patógenos (ODA et al., 2009).

Com relação à morfofisiologia, um aumento na área foliar que pode decorrer de um maior número de nós (local de formação das folhas), tende a elevar a taxa fotossintética do dossel (EGLI; ZEN-WHEN, 1991) e a produção de matéria seca total (MALEK et al., 2012). Ainda, tal aumento no número de nós, além de incrementar a superfície fotossintetizante, representa uma maior quantidade de locais para formação de flores na planta (NAVARRO JÚNIOR; COSTA, 2002).

Dentre os fatores do ambiente que influenciam o crescimento e desenvolvimento das plantas, a ocorrência de granizo e herbivoria (insetos, lebres), especialmente no início do ciclo, podem acarretar na perda de estruturas vegetativas, como as folhas cotiledonares e partes do caule. Se associado à remoção da gema terminal, a planta tem de regenerar a parte aérea a partir das gemas axilares, por meio da quebra da dominância apical (TAIZ; ZEIGER, 2012). Este processo ocorre desde que o rompimento da haste principal não aconteça na região inferior ao nó cotiledonar, uma vez que abaixo deste não existem gemas capazes de emitirem ramos, incapacitando a rebrota (MUNDSTOCK; THOMAS, 2005).

Dessa forma, tendo em vista a escassez de informações quanto à resposta das plantas de soja à ocorrência desse tipo de injúrias, objetivou-se realizar o presente trabalho para avaliar a influência da remoção, nos estádios iniciais, de diferentes estruturas vegetativas sobre a produtividade de grãos, os componentes de rendimento e características morfofisiológicas da cultura. 


\section{MATERIAL E MÉTODOS}

O trabalho foi conduzido em condições de campo na Fazenda Escola da Universidade Estadual de Londrina (FAZESC - UEL), no município de Londrina, PR, Brasil (Latitude de $23^{\circ} 23^{\prime} \mathrm{S}$; Longitude de $51^{\circ} 11^{\prime} \mathrm{W}$; Altitude de $560 \mathrm{~m}$ e clima do tipo Cfa, segundo classificação de Köppen), nas safras 2012/13 e 2013/14, utilizando-se a cultivar de soja BRS 360 RR de tipo de crescimento indeterminado.

O experimento foi semeado mecanicamente em sistema de plantio direto (SPD), em 26 de outubro de 2012 e 22 de outubro de 2013, na primeira e segunda safra respectivamente. $\mathrm{O}$ solo apresentava as seguintes características químicas na safra agrícola 2012/13, na profundidade de 0-20 cm: $\mathrm{pH}\left(\mathrm{CaCl}_{2}\right): 4,6 ; \mathrm{Al}^{+3}: 0,09 \mathrm{cmolc} \mathrm{dm}^{-3} ; \mathrm{H}^{+}+\mathrm{Al}^{+3}$ : 6,45 cmolc dm ${ }^{-3} ; \mathrm{K}^{+}: 0,61$ cmolc dm${ }^{-3} ; \mathrm{Ca}^{+2}: 3,63 \mathrm{cmolc} \mathrm{dm}^{-3} ; \mathrm{Mg}^{+2}: 1,79 \mathrm{cmolc} \mathrm{dm}^{-3}$; $\mathrm{CTC}_{\mathrm{pH}} 7,0: 12,48 \mathrm{cmolc} \mathrm{dm}^{-3}$; P: $15,23 \mathrm{mg} \mathrm{dm}^{-3}$; V: 48,31\% e M.O.: $28,85 \mathrm{~g} \mathrm{dm}^{-3}$. Os dados mensais de precipitação pluviométrica acumulada $(\mathrm{mm})$ e temperatura média do ar $\left({ }^{\circ} \mathrm{C}\right)$ durante os meses em que o experimento foi conduzido foram obtidos na estação meteorológica Morpheus, localizada na FAZESC - UEL, e são apresentados na Figura 1.

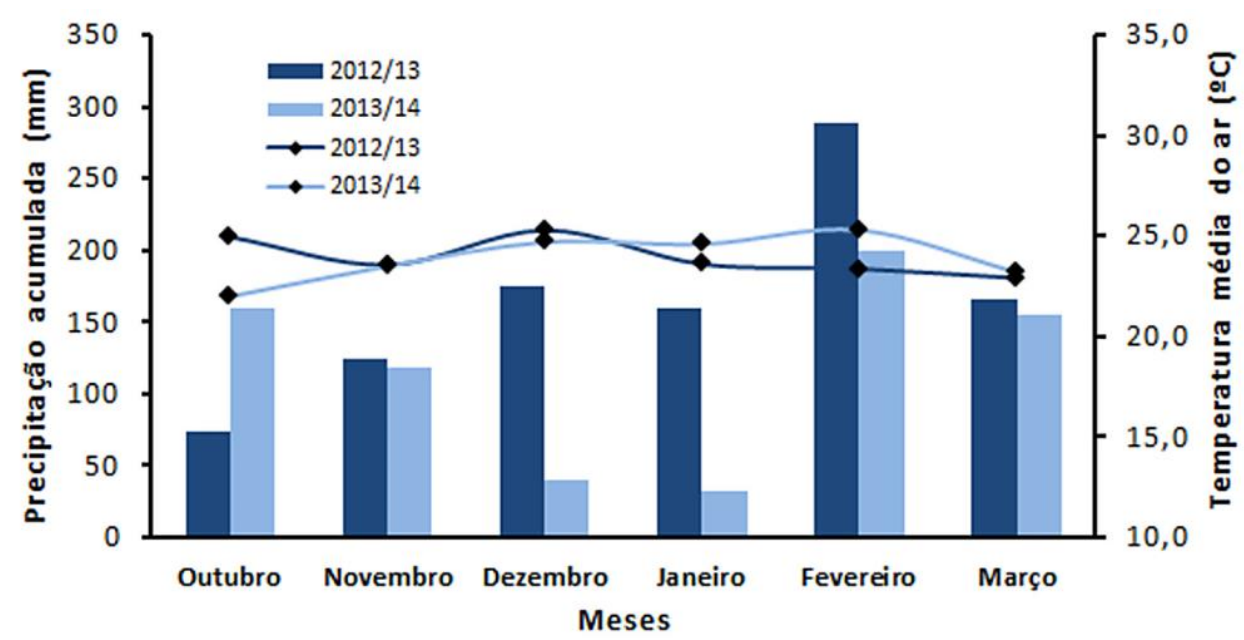

Figura 1. Precipitação pluviométrica acumulada $(\mathrm{mm})$ e temperatura média do ar $\left({ }^{\circ} \mathrm{C}\right)$ durante os meses de outubro e março nas safras 2012/13 e 2013/14, obtidas na estação meteorológica Morpheus da FAZESC - UEL. Londrina, UEL, 2014.

O delineamento experimental, nas duas safras, foi em blocos casualizados com quatro tratamentos e cinco repetições. Os tratamentos foram: 1 - Testemunha (não submetida a injúrias artificiais); 2 - Remoção dos dois cotilédones no estádio VC; 3 - Corte do caule acima do nó cotiledonar no estádio V1; 4 - Corte do caule acima do nó das folhas primárias no estádio V2. Os estádios de desenvolvimento foram determinados de acordo com a escala proposta por Fehr e Caviness (1977) e as injúrias provocadas em todas as plantas da parcela.

Em todos os tratamentos foi utilizado o espaçamento entre linhas de 0,45 m com 14 sementes $\mathrm{m}^{-1}$ linear, obtendo-se uma densidade populacional de 311111 plantas ha ${ }^{-1}$. Cada parcela constou de 6 linhas de 5,0 m de comprimento, totalizando 11,25 $\mathrm{m}^{2}$ por parcela, considerando-se como área útil aquela ocupada pelas quatro linhas centrais no primeiro ano 
e pelas duas linhas centrais no segundo ano, excluindo-se as linhas externas e $0,5 \mathrm{~m}$ de cada extremidade das linhas centrais como bordadura.

Simultaneamente à semeadura mecanizada, foi realizada a aplicação no sulco de 300 $\mathrm{kg} \mathrm{ha}^{-1}$ da fórmula 00-20-20 (N-P-K Mosaic), em ambas as safras. Os tratos culturais, como controle de plantas daninhas, pragas e doenças foram realizados pela aplicação de defensivos químicos de acordo com as recomendações propostas por EMBRAPA (2011).

Avaliaram-se, em ambas as safras, a produtividade de grãos, pelo corte e trilha manual das plantas da área útil da parcela, quando atingido o estádio R8 (FEHR; CAVINESS, 1977), obtendo-se a massa de grãos com posterior correção da umidade para $13 \%$, pelo método da estufa a $105^{\circ} \mathrm{C}$ (BRASIL, 2009), e conversão dos dados para kg ha-1 . Apenas na

primeira safra (2012/13), foram avaliados os componentes do rendimento (número de legumes por planta, número de sementes por legume e massa média de sementes) e características morfofisiológicas como o número de ramos, o número de nós da haste principal, o diâmetro do colo (em mm, por paquímetro digital), e a altura (em $\mathrm{cm}$, do colo até a região do meristema apical, por medição com fita métrica), obtidos em 15 repetições de plantas amostradas aleatoriamente dentre as colhidas em cada tratamento.

Nos tratamentos em que o caule fora cortado, considerou-se como haste principal, para a obtenção da altura e do número de nós, o ramo com maior número de nós e, quando dois ou mais ramos apresentavam igualmente o maior número de nós, considerou-se como haste principal aquele de maior comprimento.

Os dados foram submetidos à análise de variância pelo teste $\mathrm{F}(p<0,05)$ e as médias foram comparadas pelo teste de Tukey no nível de 5\% de significância com o auxílio do software estatístico SASM-AGRI (CANTERI et al., 2001).

\section{RESULTADOS E DISCUSSÃO}

Todas as características avaliadas apresentaram diferenças significativas, com exceção do número de sementes por legume e a massa média de sementes (Tabela 1). $\mathrm{O}$ fato de não se ter observado diferença entre os tratamentos para essas características se deve a pouca variação que estas apresentam em função das condições ambientais em que as plantas se desenvolvem, estando mais relacionadas à genética (NAVARRO JÚNIOR; COSTA, 2002).

A produtividade encontrada na testemunha, nas duas safras, diferiu apenas dos tratamentos 3 e 4, que não diferiram entre si, enquanto o tratamento 2, na primeira safra, diferiu apenas do tratamento 3 e, na segunda safra, dos tratamentos 3 e 4 (Tabela 2).

A resposta semelhante na produtividade entre safras está relacionada à incapacidade do genótipo em se recuperar das injúrias mesmo em condições de ambiente mais favoráveis. Moscardi et al. (2012), diferente do obtido neste estudo, observaram que a cultivar BRS 133 teve a produtividade de grãos reduzida após determinadas injúrias em uma safra, sendo que na safra seguinte, a mesma cultivar não sofreu o mesmo efeito. Estes autores atribuíram às melhores condições climáticas da segunda safra como responsáveis pela maior capacidade de tolerar as injúrias provocadas. Neste trabalho, as plantas se desenvolveram em condições Cultura Agronômica, Ilha Solteira, v.25, n.1, p.17-24, 2016 
hídricas mais adversas na segunda safra em relação à primeira, com ocorrência de veranicos nos meses de dezembro e janeiro (Figura 1), porém, mesmo assim a resposta de produtividade entre os tratamentos foi semelhante. Estes resultados também discordam de Coulter e Nafziger (2008) que, simulando injúrias por granizo em plantas de soja no estádio $\mathrm{VC}$, obtiveram diferença na produtividade de grãos apenas em 3 dos 4 ambientes em que o experimento foi conduzido, demonstrando a influência do mesmo na capacidade de manutenção da produtividade por parte das plantas injuriadas.

Tabela 1. Resumo da análise de variância para as características avaliadas na cultivar BRS 360 RR, submetida à remoção de estruturas vegetativas no desenvolvimento inicial. Londrina, UEL, 2014.

\begin{tabular}{ccc}
\hline Característica(1) & QMTrat. & $C V(\%)$ \\
\hline PROD & & \\
Safra 12/13 & $402689,2^{* *}$ & 4,45 \\
Safra 13/14 & $580771,7^{* *}$ & 13,4 \\
NLP & $232,41^{* *}$ & 17,6 \\
NSL & $0,1415^{\text {ns }}$ & 10,2 \\
MMS & $0,00004^{\text {ns }}$ & 10,4 \\
NR & $7,1722^{* *}$ & 55,35 \\
NNH & $45,733^{* *}$ & 10,6 \\
ALT & $196,29^{* *}$ & 6,29 \\
DC & $4,1337^{* *}$ & 9,57 \\
\hline
\end{tabular}

${ }^{* *}$ Significativo a $1 \%$; ${ }^{*}$ Significativo a 5\% e ns Não-significativo, pelo teste $\mathrm{F}(p<0,05)$.

QMTrat.: Quadrado médio de tratamentos; C.V (\%): coeficiente de variação.

${ }^{(1)}$ PROD: Produtividade de grãos $\left(\mathrm{kg} \mathrm{ha}^{-1}\right)$; NLP: número de legumes por planta $\left(\mathrm{n}^{\circ}\right)$; NSL: número de sementes por legume $\left(\mathrm{n}^{\circ}\right)$; MMS: massa média de sementes $(\mathrm{g})$; NR: número de ramos $\left(\mathrm{n}^{\circ}\right)$; NNH: número de nós da haste principal $\left(\mathrm{n}^{\circ}\right)$; ALT: altura $(\mathrm{cm})$; DC: diâmetro do colo $(\mathrm{mm})$.

Tabela 2. Valores médios de produtividade de grãos e componentes de rendimento da cultivar BRS 360 RR submetida à remoção de estruturas vegetativas no desenvolvimento inicial. Londrina, UEL. 2014.

\begin{tabular}{cccc}
\hline \multirow{2}{*}{ Trat. $^{(2)}$} & $\operatorname{PROD}^{(1)}\left(\mathrm{Kg} \mathrm{ha}^{-1}\right)$ & NLP $\left(\mathrm{n}^{\text {o }}\right)$ \\
& $2012 / 13$ & $2013 / 14$ & $2012 / 13$ \\
\hline 1 & $4051,86 \mathrm{a}$ & $2152,60 \mathrm{a}$ & $41,0 \mathrm{a}$ \\
2 & $3974,48 \mathrm{ab}$ & $2006,46 \mathrm{a}$ & $40,1 \mathrm{ab}$ \\
3 & $3425,35 \mathrm{c}$ & $1455,26 \mathrm{~b}$ & $34,2 \mathrm{bc}$ \\
4 & $3712,25 \mathrm{bc}$ & $1549,00 \mathrm{~b}$ & $33,4 \mathrm{c}$ \\
\hline
\end{tabular}

Médias seguidas de mesma letra nas colunas, não diferem entre si pelo teste de Tukey no nível de 5\% de significância.

(1)PROD: Produtividade de grãos $\left(\mathrm{kg} \mathrm{ha}^{-1}\right)$; NLP: número de legumes por planta $\left(\mathrm{n}^{\circ}\right)$.

${ }^{(2)}$ Tratamentos: 1- Testemunha; 2- Remoção dos cotilédones em VC; 3- Corte do caule acima do nó cotiledonar em V1; 4- Corte do caule acima do nó das folhas primárias em V2.

Com relação à remoção dos cotilédones, os resultados encontrados neste trabalho, em ambas as safras, concordam com aqueles observados por Coulter e Nafziger (2008), Bueno et al. (2012) e Moscardi et al. (2012), que também não encontraram redução na 
produtividade de cultivares de soja com este tipo de injúria no estádio $\mathrm{VC}$, demonstrando que, assim que as folhas unifolioladas estejam expandidas, os cotilédones apresentam pouca importância na manutenção da produtividade de grãos.

Quanto aos componentes do rendimento, o número de legumes por planta foi o único influenciado pelos tratamentos (Tabela 1), sendo que, assim como na produtividade de grãos, somente os cortes do caule acima do nó cotiledonar e acima do nó das folhas primárias foram capazes de reduzir esse componente em relação à testemunha (Tabela 2). Isto possivelmente contribuiu com os resultados obtidos para a produtividade nesta cultivar. O número de legumes por planta é considerado por vários autores o caráter que mais contribui para variações no rendimento de grãos (PIPOLO et al., 2005).

A altura das plantas foi menor nos tratamentos 3 e 4 em relação aos demais, enquanto os tratamentos 1 e 2 não diferiram entre si (Tabela 3), semelhante ao observado por Coulter e Nafziger (2008), em que a altura das plantas cujos cotilédones foram removidos não diferiu da testemunha.

Tabela 3. Valores médios das características morfisiológicas da cultivar BRS 360 RR submetidas à remoção de estruturas vegetativas no desenvolvimento inicial. Londrina, UEL, 2013.

\begin{tabular}{crrrr}
\hline Trat. $^{(2)}$ & $\mathrm{ALT}^{(1)}(\mathrm{cm})$ & $\mathrm{DC}(\mathrm{cm})$ & $\mathrm{NR}(\mathrm{cm})$ & $\mathrm{NNH}(\mathrm{cm})$ \\
\hline 1 & $104,9 \mathrm{a}$ & $6,6 \mathrm{bc}$ & $2,4 \mathrm{a}$ & $18,1 \mathrm{a}$ \\
2 & $102,6 \mathrm{a}$ & $6,1 \mathrm{c}$ & $1,7 \mathrm{ab}$ & $18,5 \mathrm{a}$ \\
3 & $97,9 \mathrm{~b}$ & $7,1 \mathrm{a}$ & $1,0 \mathrm{~b}$ & $16,5 \mathrm{~b}$ \\
4 & $97,5 \mathrm{~b}$ & $7,0 \mathrm{~b}$ & $0,9 \mathrm{~b}$ & $14,6 \mathrm{c}$
\end{tabular}

Médias seguidas de mesma letra, nas colunas, não diferem entre si pelo teste de Tukey a 5\%.

${ }^{(1)}$ ALT: Altura $(\mathrm{cm})$; DC: diâmetro do colo $(\mathrm{mm})$; NR: número de ramos $\left(\mathrm{n}^{\circ}\right)$; $\mathrm{NNH}$ : número de nós da haste principal $\left(\mathrm{n}^{\circ}\right)$.

(2)Tratamentos: 1- Testemunha; 2- Remoção dos cotilédones em VC; 3- Corte do caule acima do nó cotiledonar em V1; 4- Corte do caule acima do nó das folhas primárias em V2.

O diâmetro do colo apresentou relação inversa com a altura. Os tratamentos 1 e 2 proporcionaram os maiores números de nós, não diferindo entre si, seguidos dos tratamentos 3 e 4, respectivamente. As plantas da testemunha apresentaram, ainda, a maior ramificação, diferindo dos tratamentos 3 e 4, enquanto o tratamento 2 não diferiu de nenhum dos outros (Tabela 4).

Dessa forma, apesar de as plantas apresentarem a capacidade de regenerar a parte aérea a partir das gemas axilares presentes no nó cotiledonar e no nó das folhas primárias (BOERMA; SPECHT, 2004; MUNDSTOCK; THOMAS, 2005), as mesmas, quando submetidas à remoção da gema apical ainda nos estádios iniciais de desenvolvimento, não apresentaram ramificação abundante, pois os ramos que surgem dessas gemas passam a exercer dominância em suas próprias gemas axilares (TAIZ; ZEIGER, 2012), de tal maneira que, uma maior ramificação, que poderia proporcionar maior capacidade de compensar a perda do caule em termos de produção de estruturas reprodutivas, não foi observada.

Cultura Agronômica, Ilha Solteira, v.25, n.1, p.17-24, 2016 


\section{CONCLUSÃO}

A remoção dos cotilédones no estádio VC não prejudica as características morfofisiológicas nem a produtividade de grãos da cultivar de soja estudada, enquanto o corte do caule acima do nó cotiledonar e acima do nó das folhas primárias, resultando na rebrota da parte aérea a partir das gemas axilares, afeta negativamente características morfofisiológicas e a produtividade de grãos.

\section{REFERÊNCIAS BIBLIOGRÁFICAS}

BOERMA, H. R.; SPECHT, J. E. Soybeans: improvement, production and uses. 4.ed. Madison: American Society of Agronomy, 2004. 1144 p.

BRASIL. Ministério da Agricultura, Pecuária e Abastecimento - Secretaria de Defesa Agropecuária. Regras para análise de sementes. Brasília: MAPA/ACS, 2009. 399 p.

BUENO, A. F.; LEITE, N.; FRANÇA, L. F. T.; MANTOVANI, M. A. M.; ALMEIDA, N. C. S.; SILVA, G. V.; FRUGERI, A. P.; SILVA, D. M.; BORTOLOTTO, O. C. Respostas de cultivares de soja de hábito determinado e indeterminado à injúrias na fase inicial do desenvolvimento das plantas. In: CONGRESSO BRASILEIRO DE SOJA, 6., 2012, Cuiabá, MT. Anais... Brasília: Embrapa, 2012. CD-ROM.

CANTERI, M. G.; ALthAUS, R. A.; VIRGENS FILHO, J. S.; GIGLIOTI, E. A.; GODOY, C. V. SASM - Agri: Sistema para análise e separação de médias em experimentos agrícolas pelos métodos Scoft-Knott, Tukey e Duncan. Revista Brasileira de Agrocomputação, v. 1, n. 2, p.18-24. 2001. Disponível em: http://www.agrocomputacao.deinfo.uepg.br/dezembro_2001/Arquivos/RBAC_Artigo_03.pd f. Acesso em: 10 mar. 2014.

COULTER, J. A.; NAFZIGER, E. D. Yield and agronomic responses of soybean to cotyledon and unifoliolate node removal. Crop Science, v. 48, n. 1, p.353-356, 2008. Disponível em: https://www.crops.org/publications/cs/abstracts/48/1/353?access=0\&view=pdf . Acesso em: 10 jun. 2013.

EMBRAPA - Centro Nacional de Pesquisa de Soja. Tecnologias de produção de soja região central do Brasil 2012 e 2013. Londrina: Embrapa Soja, 2011. 261 p.

EGLI, D. B.; ZHEN-WEN, Y. Crop growth rate and seeds per unit area in soybean. Crop Science, $\quad$ v. $31, \quad$ n. $1, \quad$ p.439-442, 1991. Disponível em: https://www.crops.org/publications/cs/abstracts/31/2/CS0310020439 . Acesso em: 20 mar. 2013.

FEHR, W. R.; CAVINESS, C. E. Stages of soybean development. Ames: Iowa State University of Science and Technology, 1977. $12 \mathrm{p}$.

MALEK, M. A; MONDAL, M. M. A.; ISMAIL, M. R.; RAFII, M. Y.; BERAHIM, Z. Physiology of seed yield in soybean: Growth and dry matter production. African Journal

Cultura Agronômica, Ilha Solteira, v.25, n.1, p.17-24, 2016 
of Biotechnology, v. 11, p.7643-7649, 2012. Disponível em: http://academicjournals.org/journal/AJB/article-abstract/A2DF2CD33835 . Acesso em: 25 mar. 2013.

MOSCARDI, F.; BUENO, A. F.; BUENO, R. C. O. F.; GARCI, A. Soybean response to different injury levels at early developmental stages. Ciência Rural, v. 42, n. 3, p.389-394, 2012. Disponível em: http://www.scielo.br/scielo.php?pid=S010384782012000300001\&script=sci_arttext. Acesso em: 10 jun. 2013.

MUNDSTOCK, C. M.; THOMAS, A. L. Soja: fatores que afetam o crescimento e o rendimento de grãos. Porto Alegre: Evangraf, 2005. 31 p.

NAVARRO JÚNIOR, H. M.; COSTA, J. A. Contribuição relativa dos componentes do rendimento para a produção de grãos em soja. Pesquisa Agropecuária Brasileira, v. 37, n. 3, p.269-274, 2002. Disponível em: http://www.scielo.br/scielo.php?script=sci_arttext\&pid=S0100-204X2002000300006 Acesso em: 28 mar. 2013.

ODA, M. C.; SEDIYAMA, T.; BARROS, H. B. Sistemas de cultivo. In: SEDIYAMA, T. Tecnologias de produção e usos da soja. Londrina : Mecenas, 2009. Cap.7, p.71-76.

PIPOLO, V. C.; GASTALDI, L. F.; PIPOLO, A. E. Correlações fenotípicas entre caracteres quantitativos em soja. Semina: Ciências Agrárias, v. 26, n. 1, p.11-16, 2005. Disponível em: http://www.uel.br/revistas/uel/index.php/semagrarias/article/view/2262 . Acesso em: 15 jun. 2013.

TAIZ, L.; ZEIGER, E. Fisiologia Vegetal. 5.ed. Porto Alegre : Artmed, 2012. 954 p. 